\title{
The effects of the goalkeeper substitution rule as a new strategy in handball: Analysis of Men's European Handball Championship 2020
}

\author{
Hikmet Gümüş and Celal Gençoğlu* \\ Faculty of Sport Sciences, Dokuz Eylül University, Izmir, Turkey
}

Copyright: (c) 2020 H. Gümüş and C. Gençoğlu. This is an open access article licensed under the Creative Commons Attribution License (https://creativecommons.org/licenses/by/4.0/).

Background: The numerical inferiority in attacking due to the 2-min penalty is a disadvantageous situation in handball. Teams substitute the goalkeeper with a field player to tolerate this handicap. The rule change enabled the simple practicality of playing with an extra player and an empty net. Objective: The aim of this study is to analyze the effects of intervention on the additional field player strategy in elite national teams. Methods: A total of sixty-two handball matches that were played in the Men's European Handball Championship 2020 were analyzed in this study. We executed a notation analysis on in-game special periods such as the replacement of the goalkeeper with an additional field player. Eight different variables included in the analysis were goals, penalty or suspension, missed shots, technical error, received goals with an empty net, missed shots with an empty net, conceded fast-break goals and substitution failures. Results: The winning and losing teams' analysis revealed that there was a significant increase in missed shots, technical error, received goals with an empty net and received fast-break goals in the losing teams. In the comparison of the numerical asymmetry situations ( $5 \& 6$ and $7 \& 6$ with an additional field player), all parameters were significantly higher in the $5 \& 6$ situations than the $7 \& 6$ situations except for substitution failure. Conclusions: This study suggests that playing with an additional field player could provide an opportunity for advantageous attacking in the critical moments of the game and make handball a more attractive team sport in the future.

Keywords: team handball, notational analysis, additional field player

\section{Introduction}

Handball is a contact team sport that includes holding or pushing the attacker's trunk to block their invasion to one's goal area (Gorostiaga, Granados, Ibañez, González-Badillo, \& Izquierdo, 2006). According to the game rules (International Handball Federation [IHF], 2016; rule 8:1), it is allowed for defensive players to hold and perform pressure on the opponent's throwing arm to interrupt attacking players' passing or shooting, and it is also allowed to obstruct the running route to the goal by using bent arms and contact to the opponent's upper body during feints and breakthrough. After these kinds of regular contacts have resulted in a turnover, the referee calls for a free throw. More interruptions end with fouls in line with rules that have been argued for defensive success (Fasold

\footnotetext{
* Address for correspondence: Celal Gençoğlu, Faculty of Sport Sciences, Dokuz Eylül University, İİzmir Caddesi, Çolak İbrahim Bey Mah. 91/3 Sok. No:2, Seferihisar/İzmir, Turkey. E-mail: celal.gencoglu@deu.edu.tr
}

\& Redlich, 2018) and used as a defensive strategy by coaches that interfere in attacks. Karastergios, Skandalis, Zapartidis, and Hatzimanouil (2017) found that significantly higher fouls occur in the defense of winning teams in comparison to losing teams. However, injury-risked unsportsmanlike fouls such as hitting face, neck, and throat or pulling from the throwing arm and shirt require a punishment known as 2-min suspension (IHF, 2016; rule 8:4).

A penalized players' team must play with numerical inferiority within the 2-min period which leads to disadvantages in both attack and defense. Šibila (2001) observed that teams played one of four attacks with numerical inferiority or superiority in international events. Handball players' tactical behaviors (offensive and defensive playing patterns) are affected by this numerical imbalance (Schrapf, Alsaied, \& Tilp, 2017). Currently, players' exclusion-depended numerical asymmetry situations have increased in men's handball (Pueo \& Espina-Agullo, 2017). After the exclusion of a player resulted in playing with numerical inferiority for 2 mins, the offensive performances 
of teams clearly declined, and they had trouble in scoring goals (Prieto, Gómez, \& Sampaio, 2015). Marczinka (2016) highlighted the importance of tactical preparations for numerical asymmetry situations which are considered as breakpoints of the game. To tolerate the offensive weakness caused by numerical inferiority, some coaches and teams have been trying the goalkeeper-field player ("fake goalkeeper") strategy in competitive handball matches. The fake goalkeeper tactic permitted introducing an extra player when the player wore the same shirt color as the goalkeeper and showed their own number after the goalkeeper was benched in the former version of the game rules. Hereby, teams had a chance to attack with one more player with a risk of a non-guarded goal. Moreover, the extra player (fake goalkeeper) was the only athlete who could be substituted with the goalkeeper along with this tactic. In 2016, the IHF made a series of changes in game rules.

One of these rules is that the attacking team can play with an "additional field player" after taking the goalkeeper to the bench, which results in an empty goal (IHF, 2016; rule 4:6, 1st paragraph). With this rule, there is some flexibility for easy application of the rule such as that the additional player does not need to wear any different shirt, and the rule enables goalkeeper's substitution with any of the players in the sideline. The additional field player rule enables not only an equal attacking chance but also an attack with numerical superiority for teams that experience troubles in scoring and problems in creating a set defense. Recently, almost three of every four teams have practiced substitution of the goalkeeper with a field player when in numerical inferiority to equilibrate against the opponent with a risk of an empty goal (Monotya, 2016). In this perspective, there are quite a few studies on using this option as a tactical option to influence the numerical symmetry within the additional field player rule.

To the best of our knowledge, few studies have been carried out on using the "fake goalkeeper" offensive strategy which is a premature version of the modern form (Beiztegui-Casado, Oliver-Coronado, \& SosaGonzález, 2019; Klett, 2014; Musa et al., 2017). In the study that investigated equal attack with an empty goal, Beiztegui-Casado et al. (2019) found that lower rates of the additional field player tactic were put into practice (927 numerical inferiority attacks / 154 with goalkeeper-field player). They found an increased likelihood of scoring a goal when this strategy was used in comparison to when it was not used. The findings of their study indicated that this strategy could favor scoring and compensate for the disadvantages of inferior offense. However, the early form of this rule permitted replacements of the goalkeeper with a field player in the case that their own number was matched (Bauer, 2016).

Only one study (Krahenbühl, Sousa, Leonardo, Galatti, \& Costa, 2019) investigated this new rule immediately after the release of the rule in the 2016 Rio Olympics. The results indicated that teams obtained no significantly positive contribution to their offensive performance in numerical inferiority situations by using the additional field player tactic. However, they also observed there was no detrimental effect caused by an unprotected goal. Nevertheless, they collected their data from only eight men's games of the 2016 Rio Olympics which limited the study. Moreover, the teams had no time to adapt to and deliver appropriate variations of this strategy because the release of the new version of the rule and the tournament's timing were very close, which would affect the outcomes of its application as a tactic. In another study, Krahenbühl, Menezes, and Leonardo (2019) examined coaches' opinions throughout the treatment of this rule as a strategic-tactical structure. After interviews with elite coaches, there was no consensus about the application of the rule. By the start of the replacement of the goalkeeper strategy, they did not observe a clear variation of the tactical application. To date, what is not yet clear is the relative importance of various factors that affect the execution of and adaptation to this tactical substitution. This seems to increase the demand for analysis and understanding of how attacks are ended and what is the outcomes of the additional field player rule as a tactical intervention. The purpose of this study was to analyze the effects of this intervention on the additional field player strategy in elite men's national teams.

\section{Methods}

A total of sixty-six handball matches that were played in the Men's European Handball Championship 2020 were analyzed in this study. All match records were accessed from the official website of the European Handball Federation (https://www.ehftv.com/us/ league/men-s-ehf-euro-2020/954). Three experienced operators who have a strong handball background as a player and in coaching executed an independent custom notational analysis. Before the analysis, a training notational analysis session was carried out with all operators. All procedures were defined for the analysis staff. During an ordinary handball match, examples of all specific actions were determined. After the training, we clarified the grey zones for conflicting decisions with a question-answer period. Every match was analyzed by only one operator (independent observers 
analyzed 22 games). Special periods such as numerically asymmetrical attacking via the additional field player strategy were considered for the notational analysis during the game. Eight different variables that are listed below were chosen for the actions in the analysis:

1. Scored goals (Goal): Scoring a goal in the attack while playing with the additional player.

2. Attained 7-m or 2-min suspension (PS): Gained 7-m or 2-min suspensions in the attacks played with the additional field player.

3. Missed shots (MS): The executed shots resulted in goalkeeper saves, block by the defense, or out of the target.

4. Technical errors (TE): The attacks end with technical failures such as traveling, offensive foul, passing or catching error, goal area violation while using the additional field player.

5. Opponents Goals in empty goal (RGEN): Goals received while applying the extra player rule before successfully substituting the goalkeeper.

6. Opponents Missed shots in empty goal (MSEN): The attack results in the opponent's opportunity to shoot on the empty goal, but out of the target.

7. Opponents Goals in the fast break (RFBG): Because of demand for an immediate substitution of the extra player with the goalkeeper, failure to transition to set defense, and a goal is received by the fast break.

8. Substitution failures (SF): Require a suspension of failure due to emerging substitution.

The variables $1-4$ were considered as results, and 5-8 were considered as consequences in this analysis. Notational analysis of all variables was carried out on six periods as 10-min periods during the game. During the additional field player situations, the analyzed specific actions were summarized for each 10-min period. The teams and games were considered as winning or losing regarding the match results.

\section{Statistical analysis}

The statistical analysis was performed using the SPSS software (Version 25; IBM, Armonk, NY, USA). The significance level was determined as $p<.05$. Descriptive data were generated for all variables. Many of the distributions were not normal so the non-parametric Mann Whitney $U$ test was used to evaluate the difference of the factors between the winning and losing teams and between the $5 \& 6$ and $7 \& 6$ situations. The Kruskal-Wallis test (as a non-parametric variance analysis) was carried out on the use of this tactic and for the succeeded or failed results. According to the periods of the game for every $5 \& 6$ and $7 \& 6$ situations, the
Bonferroni post hoc test was performed in the case of significant differences between the 10-min timelines.

\section{Results}

We separated the descriptive analysis as the positive results (Goal and PS), negative results (MS and TE), and consequences (RGEN, MSEN, RFBG and SF). The positive results were 7.04 goals/match and 1.54 $\mathrm{PS} /$ match, whereas the negative ones were $3.80 \mathrm{MS} /$ match and $3.01 \mathrm{TE} /$ match. Both positively and negatively resulted in attacks and were higher in the second half in comparison to the first half of the matches. The consequences of performing this tactic were observed as $1.56 \mathrm{RGEN} /$ match, $0.36 \mathrm{MSEN} / \mathrm{match}$, $0.48 \mathrm{RGFB} /$ match and $0.06 \mathrm{SF} /$ match. The descriptive analysis showed that 465 goals were scored by the usage of the additional field player tactic. Additionally, 102 possessions resulted in a 7-m penalty or 2-min suspension with an extra player. We observed 199 technical errors while the goalkeeper was benched, and the teams played with an additional field player. A total of 103 goals were scored against an empty net, whereas the teams missed 24 of the attempts when there was no goalkeeper at the opponents' goal. The detailed numbers of the analyzed actions along the 10-min periods are presented in Table 1.

As shown in Figure 1, the winning and losing teams' analysis revealed that the missed shots, technical errors, and received goals with empty-net parameters were significantly higher in the losing teams, by respectively: $p=.003, p=0.001$, and $p=.001$. In the comparison of the numerical asymmetry situations $(5 \& 6$ and $7 \& 6$ with an additional field player), all parameters were significantly higher in the $5 \& 6$ situations than the $7 \& 6$ situations, except for the missed shots with empty net and substitution failures (Figure 2).

The Kruskal-Wallis test was used for the comparison of the 10-min periods of the matches. This timeline analysis showed that only the PS parameter significantly higher in the 3 rd 10-min period than the 1st one in $5 \& 6$ situations (Figure $3 b, p=.026$ ). However, in the $7 \& 6$ situations, goals and MS parameters were found significantly increased in the last 10 -min period of the games in comparison to the 1st, 2nd and 3rd 10-min periods (Figure $3 \mathrm{a}$ and $3 \mathrm{c}$ ). Figure $3 \mathrm{~d}$ presents a significant increase in the technical errors in the last 10-min of the game in comparison to the 3 rd one $(p=.024)$. Also, we found that RGEN was significantly higher in the last 10-min of the games than the 1st 10-min only for the $7 \& 6$ situations (Figure $3 \mathrm{e}$ ). There was no significant difference in the MSEN, RFBG, and SF parameters in either of the $5 \& 6$ and $7 \& 6$ situations. 


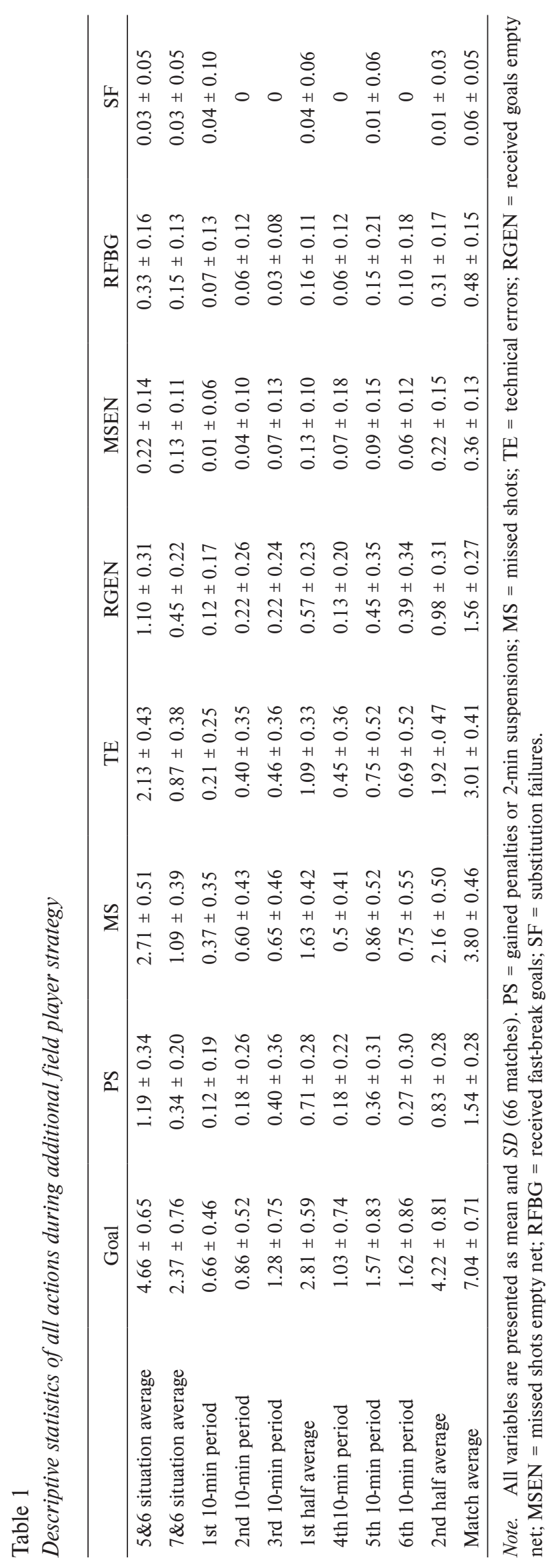

\section{Discussion}

This study was designed to determine the effects of the intervention of the additional field player tactics in elite men's handball. We investigated whether goalkeeper substitutions in numerical inferiority or symmetry situations were associated with an advantage in attacking or were just a misleading strategy that was assumed beneficial at attacks. Firstly, this study produced descriptive data by analyzing the outcomes of attacking with an empty net and extra player in men's elite handball. The descriptive analysis showed that attacks with an additional field player resulted much more positively, i.e., the total and mean numbers of the goals and PS were higher than the total and mean numbers of the missed shots and technical errors. Besides, the teams were exposed to a mean value of 2.46 negative consequences in attacking without a goalkeeper such as conceded empty-net goals or missed shots, received fast breaks goals and substitution failures. However, we only analyzed the specific periods of the games regarding the additional field player tactic. Therefore, this descriptive analysis could not represent the whole match.

Additionally, we could not compare the current results to the general $6 \& 6$ attacking proportionally. Moreover, Sylla (2020) showed that $7 \& 6$ attacks constitute only $2.4 \%$ of total attacks (2.9 attacks/ match) and $2.36 \%$ of total goals (1.3 goals/match) in youth World Championship 2019. Their seven against six attacking analysis showed that there was a similar attacking efficiency between $7 \& 6$ and all other numerical relation attacks. The findings of their analysis suggested that $7 \& 6$ attacking does not play a significant role in IHF World Championships and is not related to success while, however, exerting psychological pressure due to the empty goal (Sylla, 2020).

In another unpublished study, Björn Pazen conducted interviews with 39 elite coaches regarding $7 \& 6$ attacking, and 30 of those coaches stated negative things about this rule's consequent application as a tactic (Pazen, 2020). Some of those negative remarks consisted of increased risk of goalkeeper's injury (muscular or collision with player or post), slowed down attacking (long and stable) and decreased attractiveness of the game for spectators (empty net goals or missed shots). Supporting their findings, Korte and Lames (2019) observed that attacking without a goalkeeper in situations such as $7 \& 6$ and $5 \& 6$ (with an additional field player) situations revealed significantly longer offense time and more passes in comparison to $6 \& 6$ situations. Furthermore, Prudente, Cardoso, Rodrigues, and Sousa (2019) found that the application of this tactic led teams to get the 


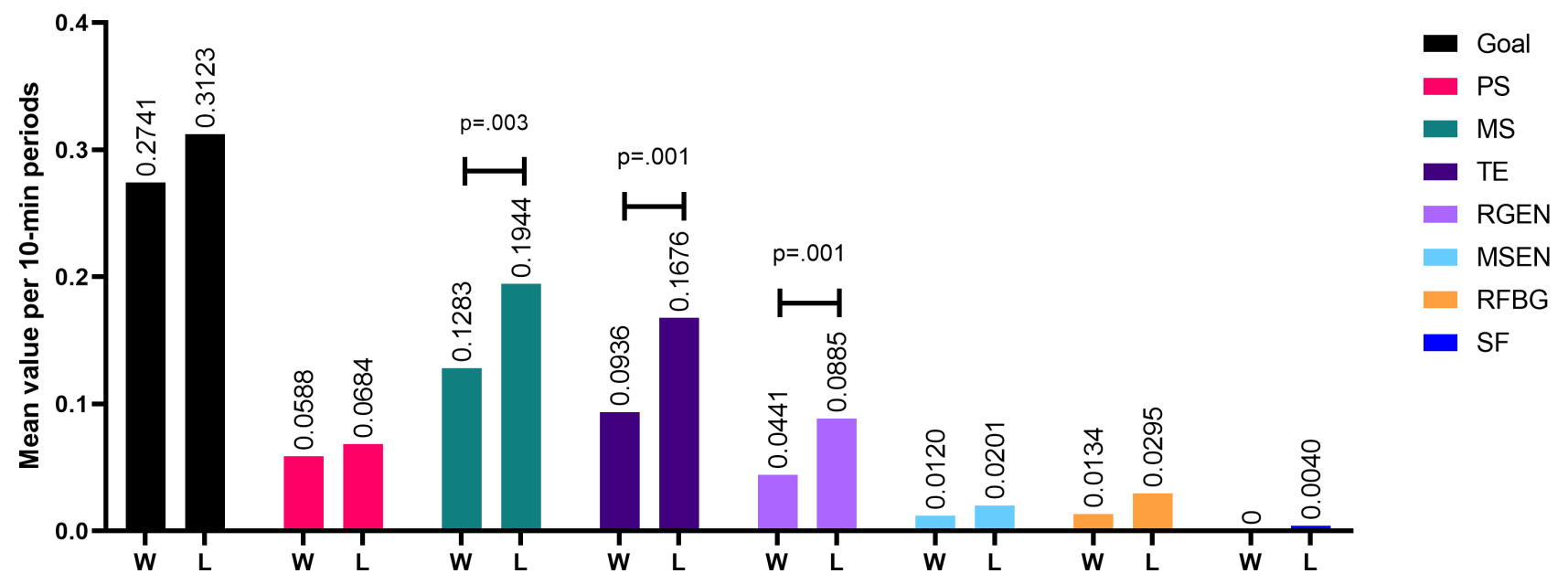

Figure 1. Differences of analyzed variables in the winner or loser teams. The number of analyzed matches was 62 after the drawing games' exclusion. $\mathrm{W}=$ Winner teams; $\mathrm{L}=$ Loser teams; PS = gained penalties or 2-min suspensions; $\mathrm{MS}$ = missed shots; $\mathrm{TE}$ = technical errors; $\mathrm{RGEN}$ = received goals empty net; $\mathrm{MSEN}=$ missed shots empty net; $\mathrm{RFBG}=$ received fast-break goals; $\mathrm{SF}=$ substitution failures.

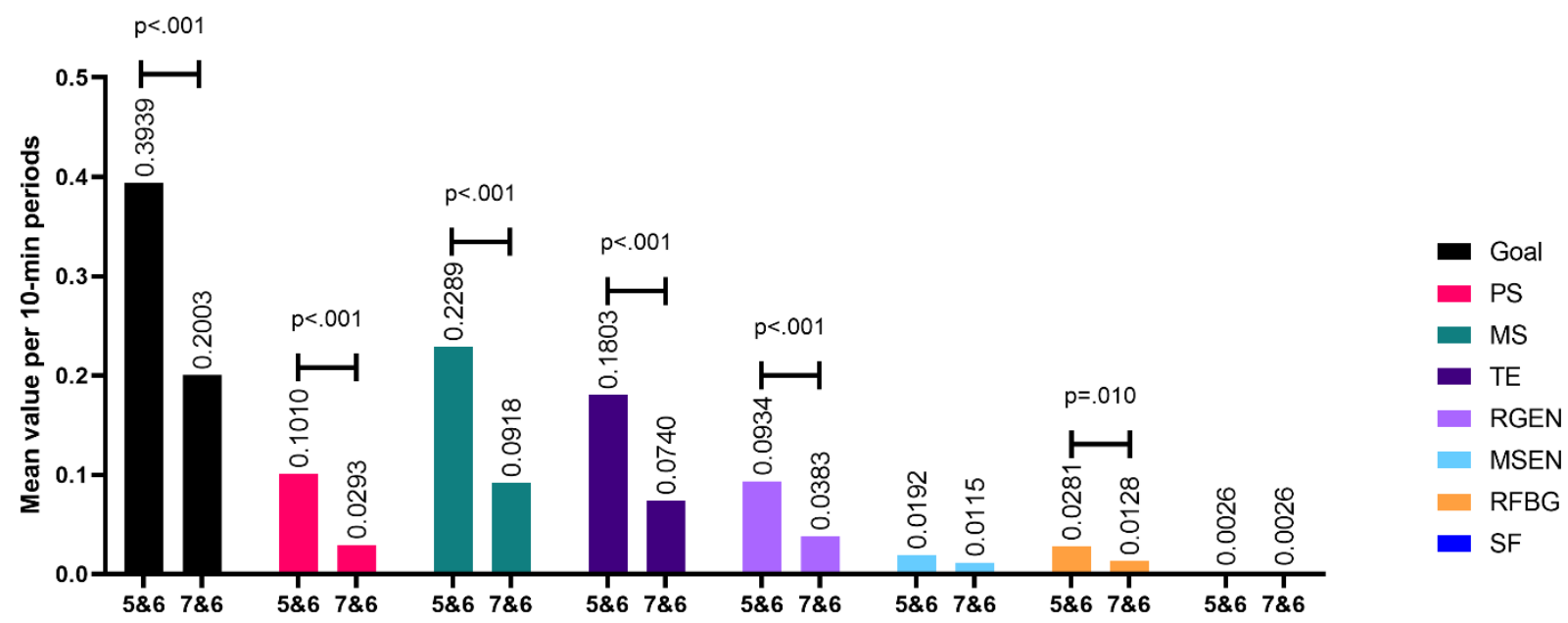

Figure 2. Comparison of all variables in $5 \& 6$ and $7 \& 6$ situations. PS = gained penalties or 2-min suspensions; MS = missed shots; TE = technical errors; RGEN = received goals empty net; MSEN = missed shots empty net; $\mathrm{RFBG}=$ received fast-break goals; $\mathrm{SF}=$ substitution failures.

opportunity to attack longer and middle back players to avoid precarious behaviors during play without a goalkeeper. Nevertheless, this rule also covers numerical inferiority situations where it is important to replace the goalkeeper instead of a sanctioned player.

Our findings showed that all parameters were significantly higher in the $5 \& 6$ situations than the $7 \& 6$ situations, except for the missed shots with an empty net and substitution failures (Figure 2). A possible explanation for this finding may be that the additional field player tactic is preferred to tolerate the disadvantages of numerical inferiority at the offense instead of attacking with seven players. This would be explained by that, playing with this tactic is more reasonable in circumstances of 2-min suspension rather than putting on the court the 7 th player. Furthermore, placement of the 7 th player on the offensive lineup (at the position of pivots or 4 back players) is also an influential element for the success or failure of the tactic. This is because, even while playing with six players in the offense including tall and large players, male handball players have no wide spaces to go beyond the defender opponents.

In a longitudinal study, Klett (2014) observed that attacking with seven players caused an increase in receiving goals with an empty net which diminished the efficacy of this tactical practice. However, it should be considered that the study was conducted 
a)

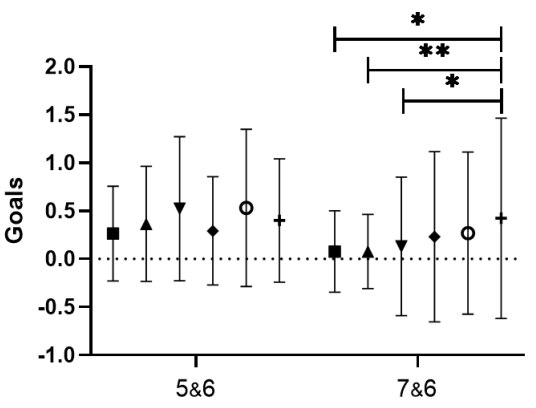

c)

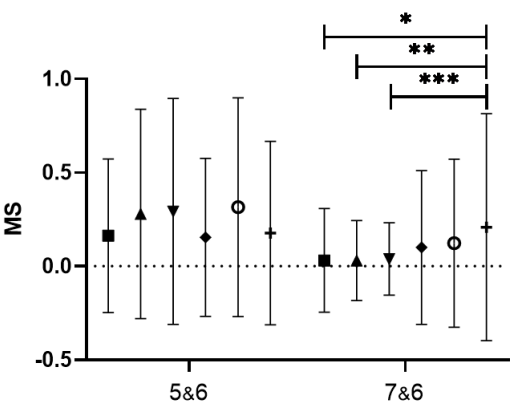

e)

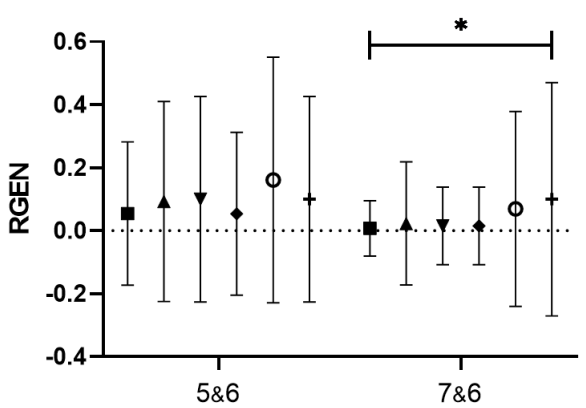

g)

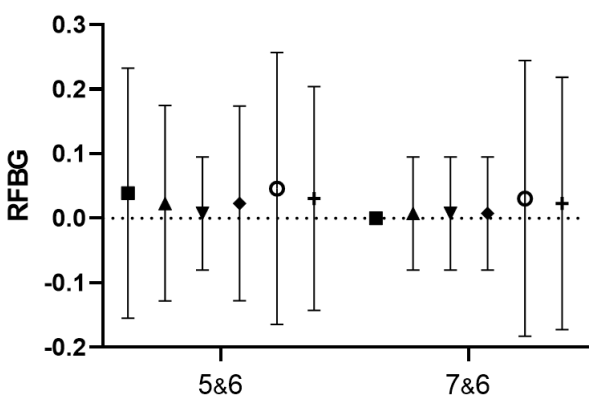

b)

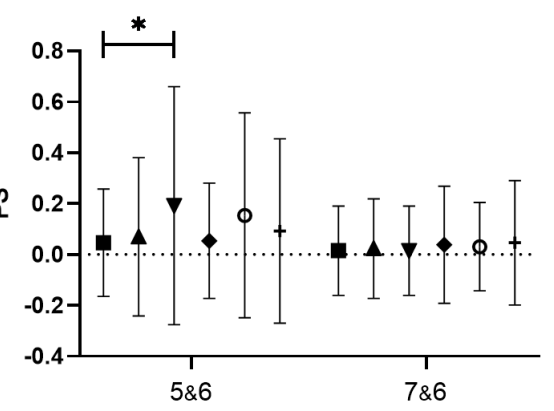

d)

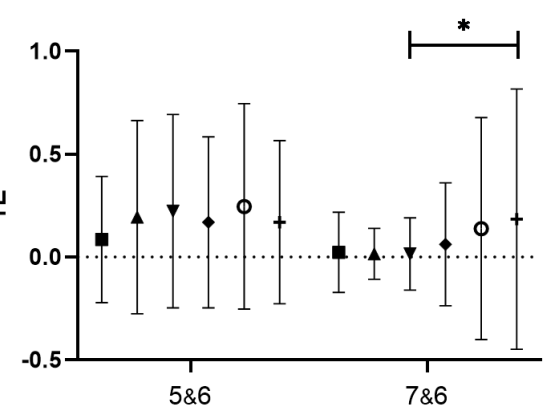

f)

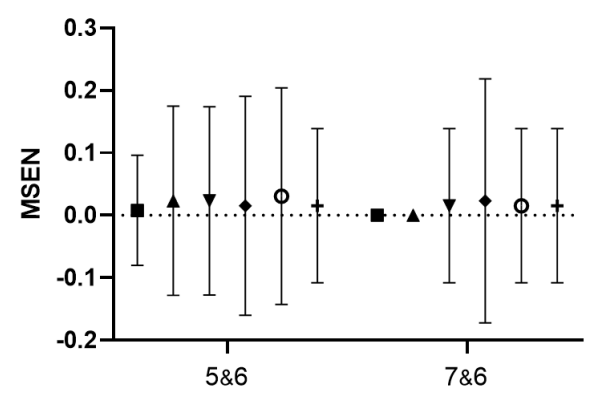

- $1^{\text {st }} 10-\mathrm{min}$

$\Delta 2^{\text {nd }} 10-$ min

$\checkmark 3^{\text {rd }} 10-\min$

- $4^{\text {th }} 10-$ min

- $5^{\text {th }} 10-$ min

$+6^{\text {th }} 10-\mathrm{min}$

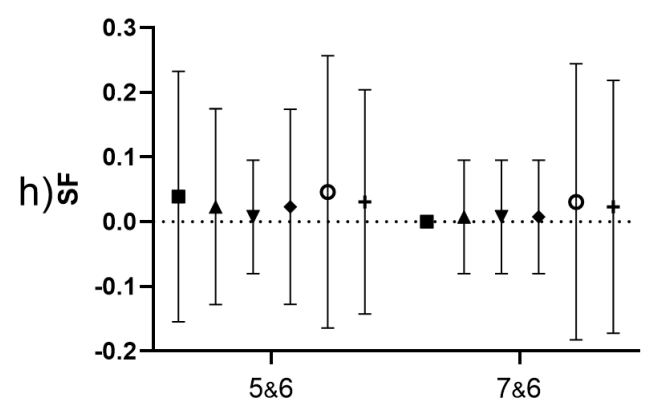

Figure 3. Demonstration of each parameter according to 10 -min periods of game in both $5 \& 6$ and $7 \& 6$ situations. $\mathrm{PS}=$ gained penalties or 2 -min suspensions; $\mathrm{MS}=$ missed shots; $\mathrm{TE}=$ technical errors; $\mathrm{RGEN}=$ received goals empty net; $\mathrm{MSEN}=$ missed shots empty net; $\mathrm{RFBG}=$ received fast-break goals; $\mathrm{SF}=$ substitution failures. a) $\left.{ }^{*} p<.001,{ }^{* *} p=.001 ; \mathrm{b}\right){ }^{*} p=.026$; c) $\left.\left.{ }^{*} p=.001,{ }^{* *} p=.004,{ }^{* * *} p=.025 ; \mathrm{d}\right){ }^{*} p=.024 ; \mathrm{e}\right){ }^{*} p=.033$. 
with old handball rules which makes the timing of the substitution and the place where the attack ends an important factor and allows players to run back to the sideline and a selected one to end up in the attack. The initial execution of this empty goal strategy was limited to a player being involved in the attack as an extra player by wearing the same colored shirt as the goalkeeper with their own number. In these circumstances, players mostly initiate the attack and turn back to the sideline and do not prefer to act like the goalkeeper themselves.

Similarly, Bachmann (2014) investigated the tactical behaviors of extra attacking players and observed that players choose to not shoot, and teams prefer to finish the attack on the opposite side of the substitution area. However, we cannot compare the findings of this study to theirs, because Bachmann's study was just descriptive and observational, and it did not include statistical results.

The findings of this study showed that winning teams and losing teams had variable results in terms of the performances of their additional field players. We observed that beneficial effects such as scored goals and gained penalty or 2-min while executing this tactic were similar between the winning and losing teams. However, the losing teams produced significantly higher hazardous outcomes i.e. missed shots, technical error, and received goals with an empty net. This result may be explained by that the losing teams performed this strategy ineffectively and ended up suffering poor consequences. The technical qualities of players such as the ability to pass pivot, timing and accuracy of the passes and taking the right position for a breakthrough are important factors and determinants of the success of the additional field player tactic. Previous studies have indicated that the efficacy of attack during numerical asymmetrical situations plays a key role in discriminating between winning or losing the match (Gutiérrez-Aguilar, Fernández, \& Borrás, 2010; Trejo Silva \& Anzano, 2018).

We observed alterations of the outcomes that occurred with the additional field player tactic that resulted in a play with an empty net according to the final periods of the matches in both numerical equality and imbalance situations. The goals scored and missed shots in the last 10 -min periods were significantly higher than those scores in the first, second, and third 10-min periods in the $7 \& 6$ situations. Further, unsuccessful attacks such as those that resulted in received empty-net goals were significantly higher in the final 10 -min period than 1 st one in the $7 \& 6$ situation. In the $5 \& 6$ situations, only the PS parameter was found significantly different within the 1 st and 3 rd 10-min periods in the first half of the matches. It is possible to explain these results with the increased frequency of this tactic and team behaviors tending to take more risk at the final moments of the matches.

In contrast, the findings by Beiztegui-Casado et al. (2019) suggested a less frequent application of this tactic in the last 10-min of the match. The possible explanation may be that at the time of their analysis of the championship, this tactic had not matured much. Therefore, teams executed it more often when the score difference was higher, rather than for closing the games. This study also demonstrated that, taking advantage of attacking with numerical superiority resulted in an increase in the scored goals and gained penalties or 2-min suspensions during the last periods in comparison to earlier periods of the game. These results supported previous research into this tactic which linked playing with seven players and attaining 7-m goals (Prudente et al., 2019).

Prieto et al. (2015) found similarly that 2-min suspensions were issued more in later periods of the game. It is possible to explain this as that, in the initial phases of handball matches, warnings or yellow cards may be used for limiting future fouls based on the regulations of handball that execute progressive punishment. These differences that occurred in the late periods of the game may be explained in part by the decrease in high-intensity defensive actions throughout the second half in comparison to the first half (Póvoas et al., 2012). Additionally, another possible explanation for inhibited attack performances such as increased unsuccessful shots and turnovers in the late periods could be that fatigue caused a diminished amount of high-intensity distance covered and reduced player load in the second half (Michalsik, Aagaard, \& Madsen, 2013; Wik, Luteberget, \& Spencer, 2017).

This study was limited to the analysis of male national handball teams. Results on the club's level of teams, which have the opportunity to work systematically on this kind of tactic, may be considered separately. The major limitation of this study is the analysis of the matches. The project was executed with a limited number of operators that conduct the notation analysis which might affect the results. Gender differences should also be considered to understand the strengths and weaknesses of this strategy. Further studies are required to establish the coach's behaviors according to the variations of this strategy and consequences for all genders and different levels of the sport. Furthermore, it would be needed to investigate the physical responses of players, especially goalkeepers, regarding this tactic. 


\section{Conclusions}

In men's elite national handball matches, teams applied the additional field players rule as a tactical approach. This study demonstrated that the losing teams had more missed shots, technical errors, received goals with an empty net and received fast-break goals as a result of using this tactic. Moreover, the goals gained penalties or 2-min suspensions and received empty-net goals parameters that might be a breakpoint increased in the later periods of the matches. These findings may suggest that an extra field player as an offensive tactical variation would affect the winning or losing status in men's handball matches. In conclusion, we conceive that playing with an additional field player in the critical periods of handball matches could change the momentum of the game.

\section{Conflict of interest}

There were no conflicts of interest.

\section{References}

Bachmann, P. (2014). Replace the goalkeeper by an additional player (Master coach thesis). The European Handball Federation, Vienna, Austria.

Bauer, J. (2016). Gastbeitrag: Der Zusätzliche Feldspieler im Handballsport - Eine Analyse [Guest contribution: The additional field player in handball sports - An analysis]. Retrieved from http://www.handballcoaching. de/2016/07/gastbeitrag-der-zusatzliche-feldspieler.html

Beiztegui-Casado, C., Oliver-Coronado, J., \& SosaGonzález, P. I. (2019). Goalkeeper-field player in situations of offensive numerical inferiority in handball: Penalty or advantage? Revista Internacional de Medicina y Ciencias de la Actividad Física y el Deporte, 19, 293-307.

Fasold, F., \& Redlich, D. (2018). Foul or no foul? Effects of permitted fouls on the defence performance in team handball. Journal of Human Kinetics, 63, 53-59.

Gorostiaga, E. M., Granados, C., Ibañez, J., GonzálezBadillo, J. J., \& Izquierdo, M. (2006). Effects of an entire season on physical fitness changes in elite male handball players. Medicine \& Science in Sports \& Exercise, 38, 357-366.

Gutiérrez-Aguilar, Ó., Fernández, J. J., \& Borrás, F. (2010). Uso de la eficacia de las situaciones de juego en desigualdad numérica en balonmano como valor predictivo del resultado final del partido [Use of the effectiveness of the game situations in inequality numerical in handball as predictive value of the final score]. E-balonmano.com: Revista de Ciencias del Deporte, 6, 67-77.

International Handball Federation. (2016). IX. Rules of the Game: a) Indoor Handball. Edition 1 July 2016. Retrieved from https://www.ihf.info/sites/default/files/2019-07/ New-Rules\%20of\%20the\%20Game_GB.pdf
Karastergios, A., Skandalis, V., Zapartidis, I., \& Hatzimanouil, D. (2017). Determination of technical actions that differentiate winning from losing teams in woman's handball. Journal of Physical Education and Sport, 17, 1966-1969.

Klett, S. (2014). Tactical innovation "7. Field player" - numerical superiority as a success indicator in handball? (Bachelor thesis). University of Stuttgart, Stuttgart, Germany.

Korte, F., \& Lames, M. (2019). Passing network analysis of positional attack formations in handball. Journal of Human Kinetics, 70, 209-221.

Krahenbühl, T., Menezes, R. P., \& Leonardo, L. (2019). Elite coaches' opinion about the additional court player and the strategic-tactical structures in handball. Motriz: Revista de Educação Física, 25, e101931.

Krahenbühl, T., Sousa, N. P. D., Leonardo, L., Galatti, L. R., \& Costa, G. D. C. T. (2019). The use of the additional field player in handball: Analysis of the Rio 2016 Olympic Games. RICYDE. Revista internacional de ciencias del deporte, 57, 295-306.

Marczinka, Z. (2016). Playing handball: A comprehensive study of the game (Updated ed.). Budapest, Hungary: Kék Európa Stúdió.

Michalsik, L. B., Aagaard, P., \& Madsen, K. (2013). Locomotion characteristics and match-induced impairments in physical performance in male elite team handball players. International Journal of Sports Medicine, 34, 590-599.

Montoya, M. (2016). Analysis of numerical inferiority actions during the positional attack phase at the 2016 Rio Olympic Games. Retrieved from http://cms.eurohandball. com/PortalData/1/Resources/4_activities/3_pdf_act/ MONTOYA_2016_OG_Play_without_Goalkeeper.pdf

Musa, V., Modolo, F., Tsuji, G., Barreira, C., Morato, M., \& Menezes, R. (2017). Participação do goleiro-linha no handebol: Análise a partir do tempo de jogo, relação numérica, posto específico e match status [Participation of the line-goalkeeper in handball: Analysis from match time, numeric relationship, specific post, and match status]. Revista Portuguesa de Ciências do Desporto, S1, 213-221.

Pazen, B. (2020, July 9). Ready for the great 7 vs 6 debate? Is it even a debate? [Audio podcast]. Retrieved from https://handballhour.libsyn.com/ episode-79-the-great-7-vs-6-debate

Póvoas, S. C., Seabra, A. F., Ascensão, A. A., Magalhães, J., Soares, J. M., \& Rebelo, A. N. (2012). Physical and physiological demands of elite team handball. Journal of Strength and Conditioning Research, 26, 3365-3375.

Prieto, J., Gómez, M. Á., \& Sampaio, J. (2015). Players' exclusions effects on elite handball teams' scoring performance during close games. International Journal of Performance Analysis in Sport, 15, 983-996.

Prudente, J. N., Cardoso, A. R., Rodrigues, A. J., \& Sousa, D. F. (2019). Analysis of the influence of the numerical relation in handball during an organized attack, specifically the tactical behavior of the center back. Frontiers in Psychology, 10, 2451.

Pueo, B., \& Espina-Agullo, J. (2017). Relationship between exclusions and final results in European championships, world championships and Olympic games in men's handball 1982-2014. Journal of Physical Education and Sport, 17, $1158-1162$. 
Schrapf, N., Alsaied, S., \& Tilp, M. (2017). Tactical interaction of offensive and defensive teams in team handball analysed by artificial neural networks. Mathematical and Computer Modelling of Dynamical Systems, 23, 363-371.

Šibila, M. (2001). Visions in handball - "Visions for the $3 r d$ decade", proposals for the workshop and the discussion during the 2001 Lecturers' Seminar. Retrieved from https://members.ehf.eu/community/activities/download. ashx? reason $=$ ehfcanFile\&id $=1216$
Sylla, Y. (2020). Playing seven against six: More than positioning on court [Video file]. Retrieved from https://www. youtube.com/watch?v=LYb506hq0PU

Trejo Silva, A., \& Anzano, A. P. (2018). Offensive efficacy in numerical inequality situations in female handball. Apunts. Educación Física y Deportes, 131, 95-107.

Wik, E. H., Luteberget, L. S., \& Spencer, M. (2017). Activity profiles in international women's team handball using PlayerLoad. International Journal of Sports Physiology and Performance, 12, 934-942. 